\title{
LAS ESCULTURAS DEL RETABLO MAYOR DE LA CAPILLA DE LA ENFERMERÍA DE LA V.O.T. DE MADRID *
}

\author{
POR \\ JUAN NICOLAU CASTRO \\ Academia de Bellas Artes de Toledo
}

La escasez de estudios sobre la escultura tradicional española es tema que con el correr de los años y con las tan pretendidas reformas litúrgicas, con el consiguiente cambio de ubicación, se está tornando un asunto casi dramático y esto tal vez sea especialmente cierto con la escultura madrileña de la que tanto queda por estudiar y de la que, a pesar de infinitos avatares, restan más piezas de las que una mirada superficial imagina.

Pretendemos en este artículo poner un grano de arena estudiando y dando a conocer al autor del conjunto de esculturas que adornan el retablo mayor de la Enfermería de la V.O.T. que un feliz hallazgo documental y el reciente estudio de María Luisa Tárraga nos ha permitido desvelar ${ }^{1}$.

La pequeña capilla de la Enfermería es pieza hermosa a pesar de su sencillez y cuenta con la ventaja, casi milagrosa, de habernos llegado intacta. Don Elías Tormo con su parquedad habitual, no exenta en este caso de un cierto laconismo, dice de ella «el aspecto es grato, sin complicaciones ni lujo, y bien típico» ${ }^{2}$. El mismo investigador nos apunta que el autor de los planos bien pudo ser Teodoro Ardemáns y que la obra se acometió a partir de 1693 por José Arroyo y, muerto éste, por el arquitecto Felipe Sánchez.

Virginia Tovar nos informa, de modo documentado y definitivo, sobre su construcción cuyas obras, sacadas a concurso, comienzan efectivamente en 1693 por el arquitecto José Arroyo que había hecho su aprendizaje como aparejador de Pedro de la Torre ${ }^{3}$. Pero Arroyo muere a comienzos de 1695 tasando lo que había hecho, entre otros Teodoro Ardemáns, a quien Tormo, como hemos visto, atribuye las trazas. Muerto el arquitecto se hizo cargo de

\footnotetext{
* Agradezco encarecidamente a la Dra. María Luisa Tárraga, que proyecta un extenso trabajo sobre Julián de San Martín, su desinteresado apoyo y sus orientaciones para llevar adelante este trabajo.

1 Archivo Diocesano de Toledo. Documentos sobre restauración de templos. Memorial del escultor Julián de San Martín.

María Luisa Tárraga, «España y América en la escultura cortesana de la segunda mitad del siglo XVIII: Corrientes recíprocas de influencia», pp. 217-272 en Relaciones Artísticas entre España y América, C.S.I.C., Instituto «Diego Velázquez», Marid, 1990.

2 Elías Tormo, Las Iglesias del Antiguo Madrid, Instituto de España, 1972, p. 63.

3 Virginia Tovar Martín, Arquitectos madrileños de la segunda mitad del siglo XVII, Madrid, Instituto de Estudios Madrileños, 1975, pp. 342 y 354.
} 
las obras el interesante arquitecto zaragozano Felipe Sánchez a partir de 1695 pero expone sus dudas sobre la consistencia de lo realizado por su antecesor. Por cuenta de la V.O.T. dieron su parecer distintos maestros coincidiendo con la opinión de Felipe Sánchez y finalmente éste contrata la obra a comienzos de ese año de 1695 respetándose en la planta lo proyectado por su antecesor. El templo se consagraba en 1699. Siguiendo la descripción de Virginia Tóvar la planta se concibe en forma de nave de salón con breve crucero y original cúpula, cubriéndose con bóveda de cañón con lunetos. Pero, sin duda, lo más característico del pequeño edificio es su original fachada con cierto carácter borrominesco que la hace destacar en lo madrileño de la época. A comienzos de 1696 se presentaban proyectos para la custodia y se contrataba el dorado del retablo mayor ${ }^{4}$.

Este primitivo retablo se debió demoler en el último tercio del siglo XVIII sustituyéndose por el actual (fig. 1) que según Tormo realiza el ensamblador Patricio Rodríguez siguiendo proyecto de Francisco Sánchez, quien a su vez había sido discípulo de Ventura Rodríguez 5 . El retablo presenta una estructura claramente neoclásica que el arco de remate, adornado con casetones y rosetas acentúa, todo él trabajado en madera que se policroma imitando mármoles. No obstante el recuerdo de esquemas de Ventura Rodríguez es patente en una serie de elementos barrocos que aún perduran. Este tipo de retablo se difundió de modo extraordinario a finales del siglo XVIII y comienzos del XIX por Madrid e invadiendo gran parte de la península, siendo especialmente abundante en Galicia donde el tipo arraiga de manera especial ${ }^{6}$. El esquema es muy sencillo, de tres calles enmarcada la central por una pareja de grandes columnas lisas de capiteles corintios y gran entablamento que da al conjunto un aire de arco de triunfo clásico. La nota decorativa la pone el frontón partido adornado con dos grandes ángeles que corresponden aún al mundo rococó y el gran arco de medio punto, pegado al muro y llegando hasta la bóveda que se adorna con las rosetas doradas. La calle central está enteramente ocupada por una gran hornacina que alberga una de las más espléndidas tallas madrileñas de la Inmaculada (figs. 2 y 3 ) que resulta también de sabor mucho más rococó que neoclásico. La Virgen se alza sobre un globo, cuajado de doradas estrellas, que surge entre grandes masas de nubes y cabezas y cuerpecillos de serafines, todo de deliciosa talla. Su inspiración en obras de los mejores imagineros del siglo es muy clara, de modo especial nos parece percibir su huella en el mundo de Juan Pascual de Mena, hay cabezas de angelillos cuyas diminutas alas describen unas curvas que vemos repetidas en este escultor toledano y no podemos tampoco olvidar las masas de nubes sobre las que se elevan algunas de sus Vírgenes, singularmente las de la Consolación y Correa de la parroquia de Ntra. Sra. de la Esperanza de Madrid o la del Rosario de la parroquia de Rascafría, procedente de el vecino Paular ${ }^{7}$. Sobre la gran peana se alza la Virgen vesti-

\footnotetext{
Idem, p. 357 .

Elías Tormo, o.c., p. 63.
}

Ramón Guerra de la Vega, Guía para visitar las Iglesias y Conventos del Antiguo Madrid, Ayuntamiento de Madrid, 1996, p. 208. En esta reciente obra, ilustrada con muy bellas fotografías, se sigue casi al pie de la letra el texto de Tormo.

Fernando Chueca Goitia, «Ventura Rodríguez y la Escuela Barroca Romana» en el catálogo de la exposición El Arquitecto D. Ventura Rodríguez (1717-1785), Museo Municipal de Madrid, 1983. Es especialmente interesante para el tema que aquí tratamos el apartado final del artículo, titulado «Algo sobre la decoración arquitectónica y los altares de V. Rodríguez», pp. 29-33.

6 Aunque son infinidad los ejemplos que podríamos citar nos interesa destacar los últimos retablos que José Ferreiro y sus discípulos o imitadores dejan en tierras alejadas de la provincia de Orense, como el de San Pedro de la Torre, La Mezquita y el de la limítrofe aldea zamorana de Hermisende, junto a Puebla de Sanabria, donde el escultor muere en 1830 .

7 Juan Nicolau de Castro, «El escultor Juan Pascual de Mena», Goya, ‥ 214, 1990, pp. 194-204. 


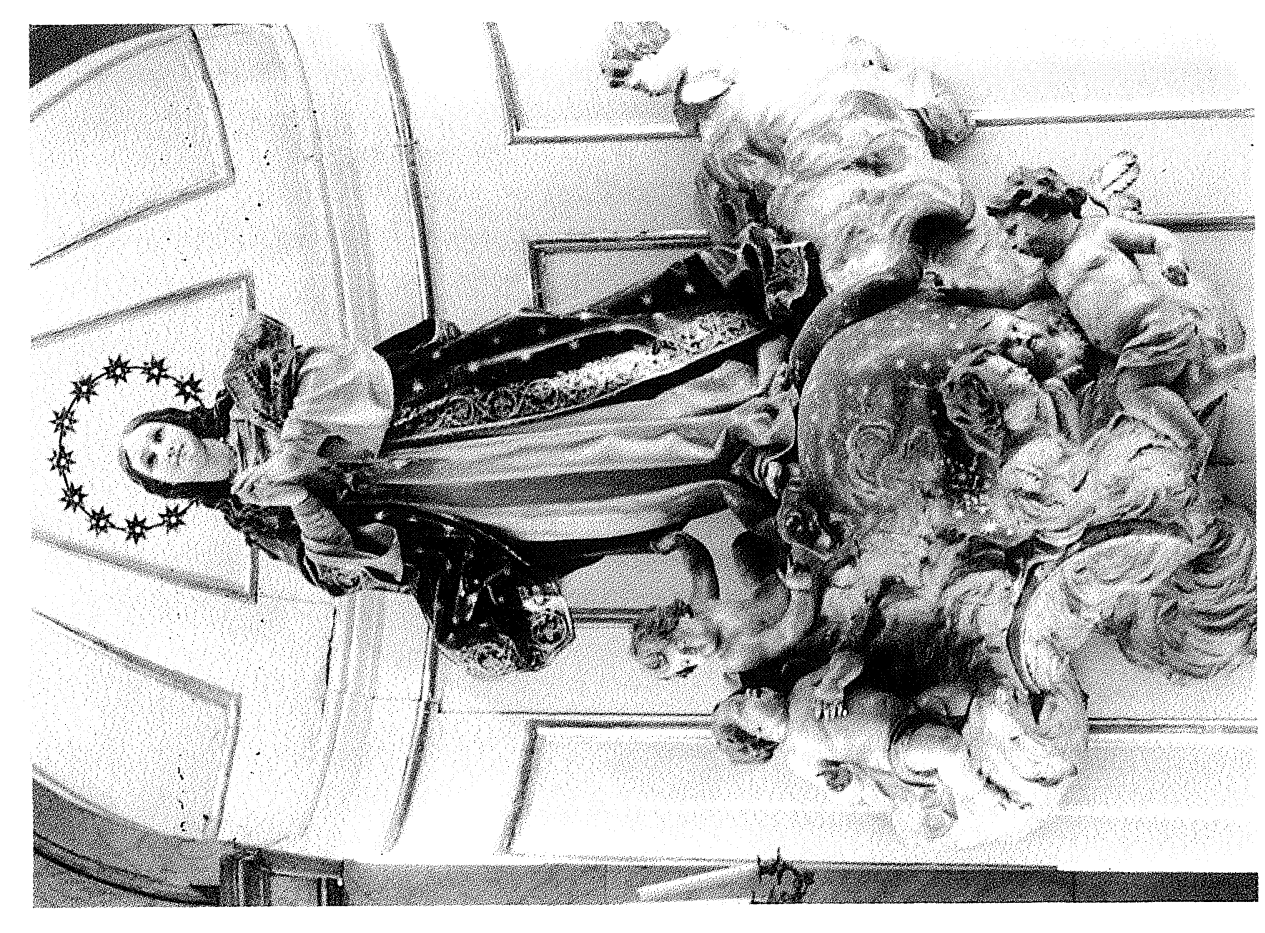

N

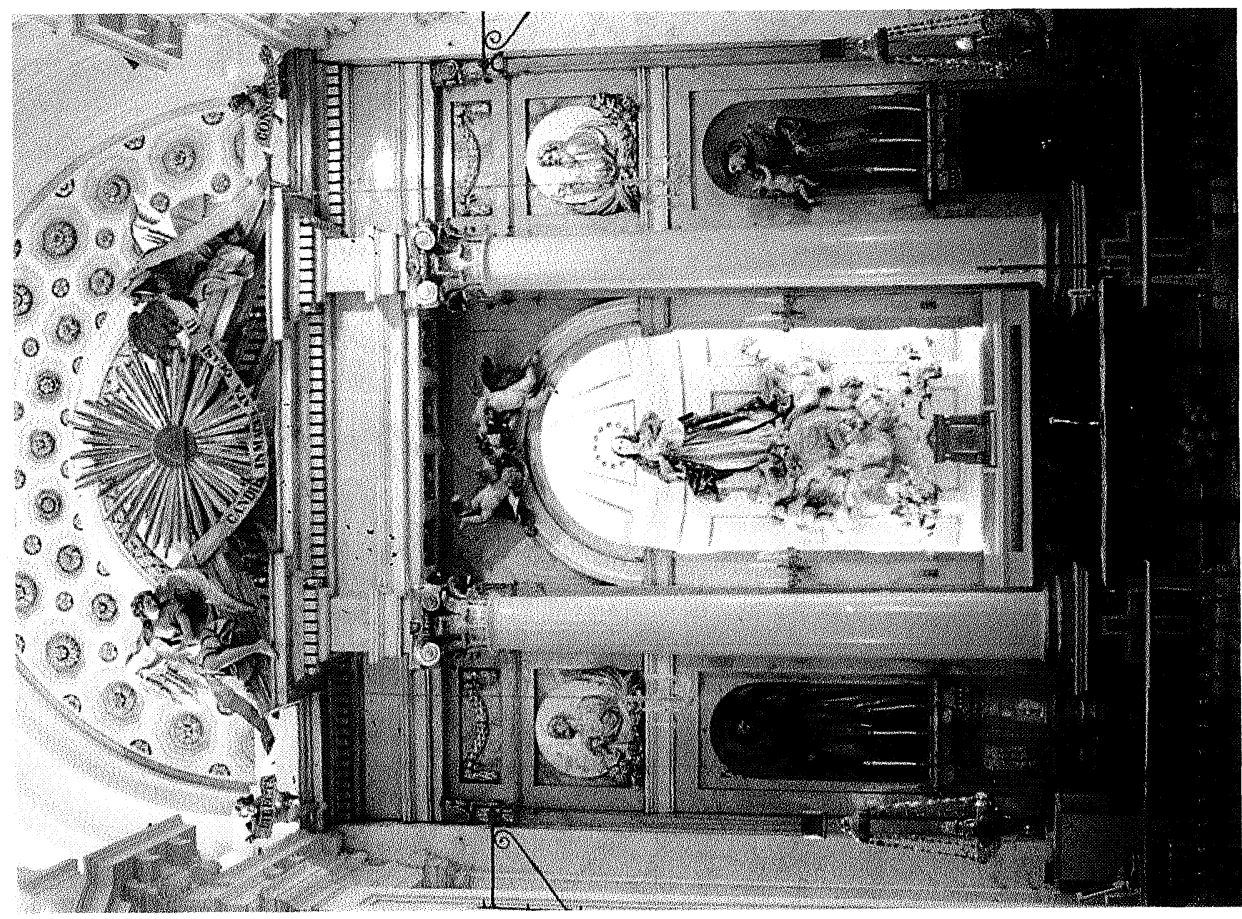

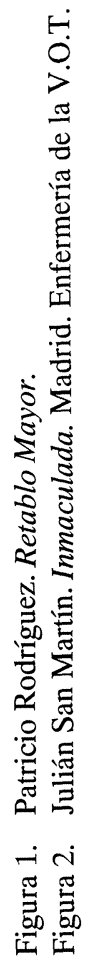


da, como es tradicional, con vestidura blanca y manto azul cuajado de estrellas y orlado de rica cenefa dorada, todo el conjunto resulta especialmente movido, con un cierto sentido ascendente, y buscando efectos decorativos y refinados. Su rostro, enmarcado por larga cabellera y muy suavamente tallado, mira ligeramente hacia lo alto. Pese a la indiscutible belleza del grupo que ya Elías Tormo proclama ${ }^{8}$, se aprecia en esta Inmaculada una indiscutible impronta murillesca que la hace casi punto de partida del almibaramiento que tal influencia va a reportar a las figuras de esta advocación a todo lo largo del siglo XIX y que llegará plenamente hasta casi nuestros días. Finalmente no nos resistimos a apuntar ese cierto aire de familia que vemos con la Inmaculada del Palacio Arzobispal sevillano que talla el escultor portugués Cayetano de Acosta en 1776, fecha muy cercana a esta de Madrid, aunque la ventaja artística indiscutible quede para el lusitano ${ }^{9}$.

Sobre la clave del arco de esta hornacina central aparecen dos figuras de angelillos (fig. 5) que portan una corona de flores en gracioso y delicado movimiento que unos ligeros paños azules acentúan. Aquí, nos encontramos, a nuestro juicio, con una de las partes más gratas de todo el conjunto, clara muestra de esa corriente internacional que en el siglo XVIII invade Europa y que tal vez, como pocas veces en el arte español, nos lleva a ese mundo refinado del rococó de Centroeuropa que los grabados llevan a todos los rincones.

Ya hemos indicado cómo este cuerpo central remata en frontón partido en cuyos don ángulos laterales se asientan sendos ángeles mancebos (fig. 4), de tamaño natural, portando una gran cinta con una inscripción alusiva a la Inmaculada en lo que se ven ayudados por dos pequeños angelillos que aparecen sobre el entablamento en los extremos de la cornisa. Los ángeles mancebos van envueltos en leves túnicas azuladas con las vueltas blancas, tienen espléndidas cabezas de mirada de ensueño, cabellos largos y movidos y se nos aparecen en posturas inestables en las que el escultor ha buscado por encima de todo ricos efectos decorativos, lo que ha logrado plenamente. Aquí de nuevo nos parece clara la influencia de Juan Pascual de Mena, de manera muy especial en el conjunto que este escultor esculpe para el retablo del Monasterio de las Góngoras. Entre los ángeles, como es acostumbrado en este momento, un gran sol de decorativos rayos muestra en su interior el triángulo trinitario.

Las calles laterales son mucho más estrechas y en ellas el espacio se encuentra compartimentado en cuatro partes, las puertas de la sacristía, sendas hornacinas con las esculturas de San Francisco de Asís y San Antonio de Padua (figs. 6-9), dos grandes medallones con las efigies de San Pedro y San Pablo (figs. 10 y 11) y un reducido espacio rectangular que se adorna con una guirnalda de laurel. Las puertas de color verdoso se adornan con relieves de distintos objetos litúrgicos dorados. Sobre la puerta derecha, en la hornacina, se ubica una magnífica escultura de San Antonio (figs. 7 y 8) llevando al Niño Jesús sobre el brazo derecho de una manera inestable en la que el escultor ha buscado claramente un efecto rebuscado y elegante. El Santo es de una alargada y estilizada silueta y se vuelve ligeramente hacia el Niño al que dirigie la mirada arrobada. El Niño, digno compañero de los que portan la corona sobre la Inmaculada o se mueven en la peana alza los brazos graciosamente dirigiéndolos al rostro del Santo como pretendiendo hacerle una caricia. La figura infantil aporta al conjunto su gracia y un tono alegre de policromía con el moreno de su carnación, el rubio de sus cabellos y el tono rosado del diminuto paño de pureza. El conjunto resulta una imagen espléndida en la que resaltan las dotes de elegancia del escultor.

8 Elías Tormo, o.c., p. 63.

9 Enrique Valdivieso, «Una Inmaculada inédita de Cayetano de Acosta», Archivo Hispalense, N. ${ }^{\circ}$ 196, 1981, pp. 143-45. 

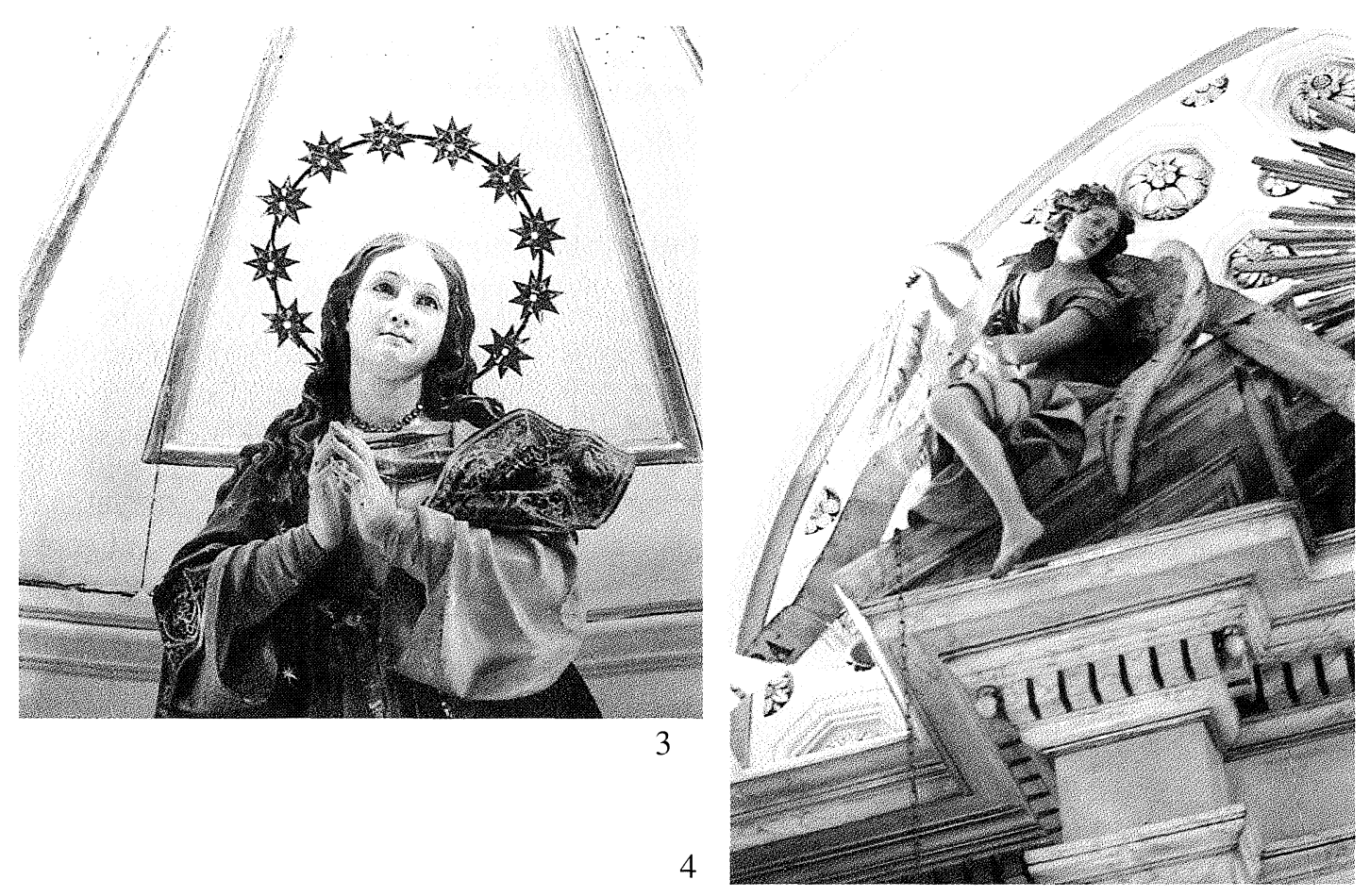

5

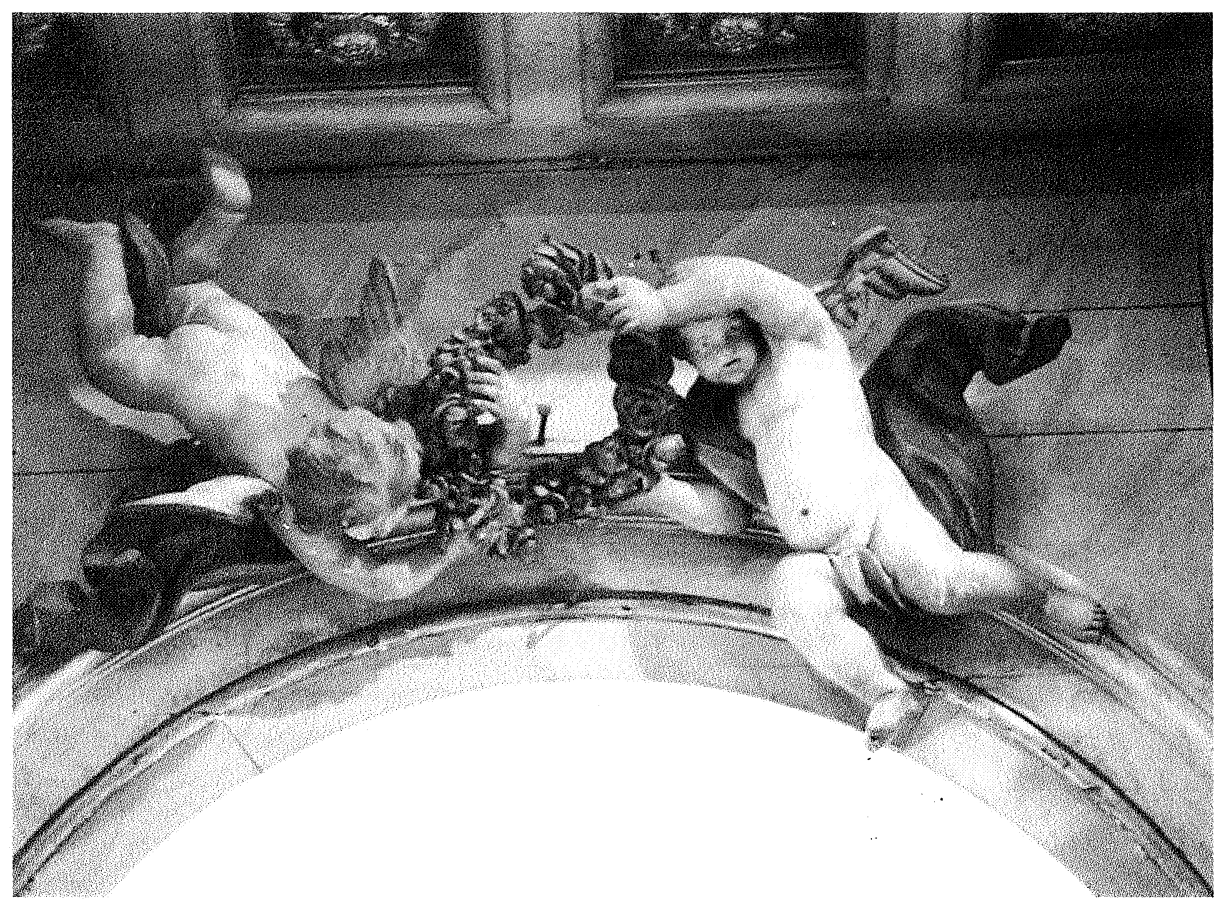

Julián San Martín.

Figura 3. Inmaculada, detalle.

Figura 4. Ángel Mancebo.

Figura 5. Ángeles, detalle. Madrid. Enfermería de la V.O.T. 

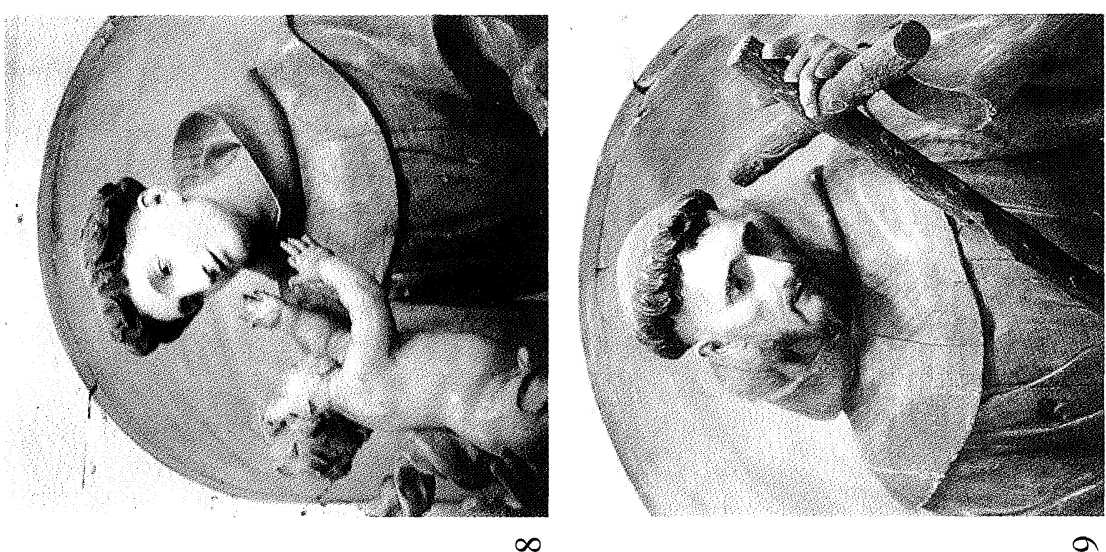

a

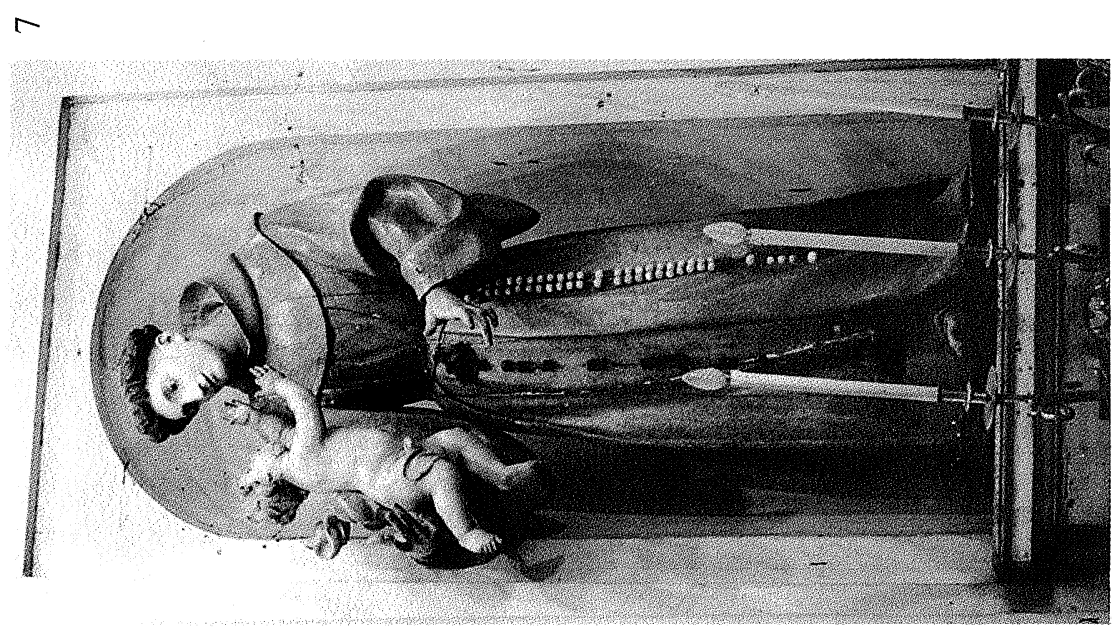

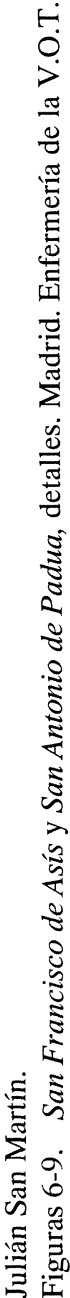

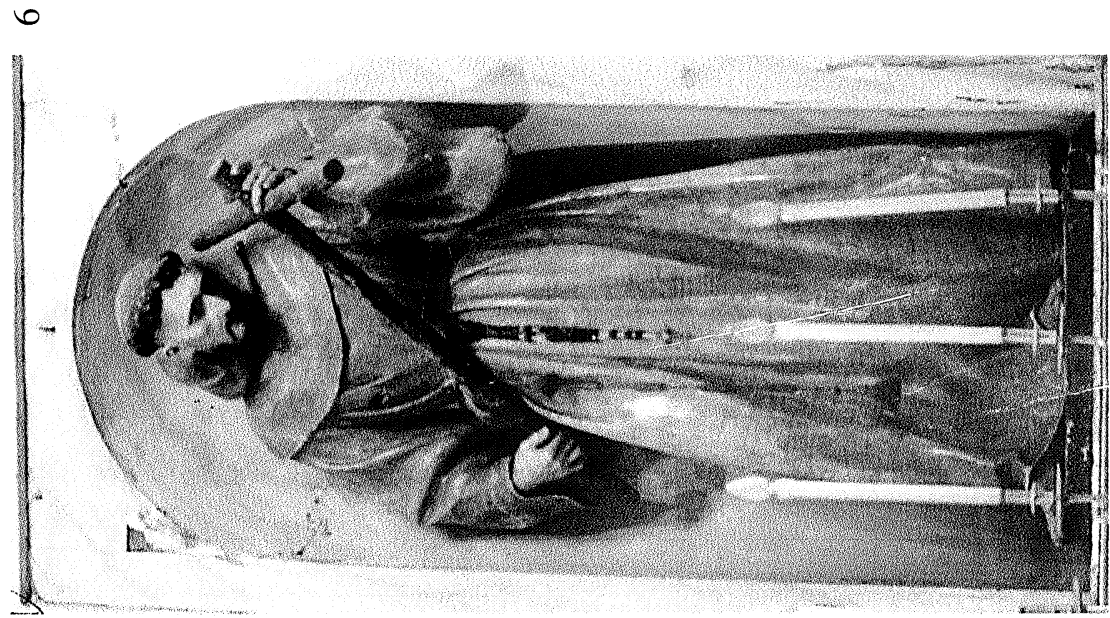


Sobre la hornacina de San Antonio, es un espacio cuadrado de fondo policromado imitando mármol verde, el escultor colocó un gran medallón enteramente dorado, de algo menos de medio cuerpo, representando al apóstol Pablo (fig. 11) portando en sus manos un libro cerrado y la tradicional espada. El Santo está esculpido de lado y muestra la cabeza de frente por encima del hombro como mirando a algún posible espectador. Viste túnica y manto que deja en gran parte libre la espalda. Su rostro se enmarca con generosa cabellera y larga y partida barba entre la que destaca la boca entreabierta. Es pieza de gran dignidad donde la figura se muestra en actitud solemne y seria como en un relieve clásico que el dorado acentúa y contrasta vivamente con la gracia un tanto sensual del San Antonio colocado bajo él. Enmarcando el tondo, por la parte de abajo, ramas de palma y laurel entrelazadas hacen referencia a su martirio y victoria. Figura de gran dignidad en la que el escultor hace gala de sus conocimientos y estudios académicos, de muy posible inspiración en grabados, que resulta agradable pero mucho menos personal y sentida que las otras esculturas de inspiración tradicional que pueblan el retablo. Sobre esta figura, como en la calle paralela, destacando en el mismo fondo policromado de mármol verde una guirnalda de laurel dorada es una clara y fría concesión al neoclasicismo triunfante.

La calle paralela del lado izquierdo presenta, como ya hemos dicho, el mismo esquema. Puerta con las consabidas piezas litúrgicas talladas y doradas y gran hornacina central con la figura de San Francisco de Asís (figs. 6 y 9) portando una gran cruz de palo en las manos que cruza de modo diagonal por delante del pecho. En esta figura el canon alargado que ya vimos en el San Antonio se acentúa aún más, tal vez debido en parte a que aquí resulta menor el tamaño de la cabeza de alargado perfil que la barba y bigote acentúan. De pómulos muy marcados y mejillas arrugadas y hundidas lo mismo que las cuencas de los ojos en las que éstos resaltan pequeños fijándolos con mirada un tanto extraviada en la cruz que lleva en las manos. Resulta escultura en extremo dramática ante la cual surge inconsciente el recuerdo de El Greco en algunos santos muy concretos de su producción, y en la que resalta su concentrado y casi duro ascetismo frente a la alegría que transmite el San Antonio. Sobre el San Francisco tenemos la medalla que en esta calle representa a San Pedro (fig. 10). Aquí, en contraste también con el San Pablo, el Santo aparece de frente con las manos unidas en una anhelante súplica que con gran dramatismo expresa el rostro, de factura también más pictórica, captado en el momento en que toma conciencia de su traición. Su barba revuelta y sus cabellos cortos y ralos acentúan aún más el dramatismo de la figura. Enfrente, suspendidas en el espacio, aparecen las tradicionales llaves y sobre ellas se insinúa apenas la silueta del gallo. Las guirnaldas de palma y laurel que adornan la medalla y su colocación bajo ella son en todo semejantes a las del lado derecho pero hay en toda esta calle un mayor dramatismo en las dos figuras que tal vez haya sido buscado conscientemente por el escultor.

Nos encontramos aquí, en este retablo de la Enfermería de la V.O.T., con un conjunto escultórico muy notable y que nos pone sobre la pista de un escultor Julián de San Martín casi desconocido, en realidad al margen de la escultura de su Beata María Ana de Jesús poco más se venía citando de él, y que habrá que sacar del olvido ya que su producción, como recientemente ha demostrado María Luisa Tárraga fue numerosa ${ }^{10}$ llegando a enviar algunas piezas a América. De todos modos en este conjunto de la Enfermería nos resulta per-

${ }^{10}$ María Luisa Tárraga, o.c. Además de en esta obra aportan noticias sobre Julián San Martín, Jesús Urrea, «La escultura en la Corte, 1780-1800», pp. 111-140, en el catálogo Tolsá, Gimeno, Fabregat. Trayectoria artística en España. Siglo XVIII, Generalitat Valenciana, 1989, M. Osorio y Bernard, Galería biográfica de artistas españoles del siglo XIX, Madrid, 1883-1984, p. 629 y Conde de la Viñaza, Adiciones al Diccionario Histórico... de Cean Bermúdez, T. III, p. 352, Madrid, 1894. 
sonalidad compleja y en él se aúnan una serie de tendencias que claramente marcan el momento que se vivía en el mundo de la escultura. Son espléndidas y las podemos encajar en el mejor momento de la escultura tradicional religiosa española las figuras de San Antonio y San Francisco, responden plenamente al rococó los ángeles que coronan el retablo y esas deliciosas figurillas que rematan la hornacina de la Virgen o se mueven en su peana y la Inmaculada resulta de algún modo desconcertante para el momento por esa excesiva finura que, como ya hemos repetido, lleva al almibaramiento. Los tondos con los relieves de San Pedro y San Pablo son típicamente deudores del neoclasicismo aunque en el rostro del San Pedro vuelve a surgir Julián San Martín, recurriendo a una frase castiza, la veta brava, aun teniendo presente, como ya dijimos, su más que probable inspiración en grabados. Todo el conjunto queda además espléndidamente enmarcado en ese retablo tan significativo como la propia escultura, neoclásico por su esquema, por la utilización de madera policromada imitando mármoles en su decoración pero en el que algunos elementos de decoración rococó son también evidentes.

Según, sobre todo, el tan citado trabajo de María Luisa Tárraga sabemos que Julián San Martín fue escultor que vivió poco pero trabajó mucho. Él nace en el pueblecito de Valdelacuesta, en la provincia de Burgos, en 1762 y al parecer muere en Madrid en 1801. Las fechas de estas esculturas, que ahora estudiamos, hay que situarlas en la década de los ochenta, en momento en el que el escultor es aún bastante joven. Hace poco tiempo localizamos un memorial del escultor, tal vez dirigido a Melchor de Jovellanos, en el archivo diocesano de Toledo fechado concretamente el 5 de julio de 1789 y en él Julián San Martín afirma textualmente haber tallado «toda la escultura del retablo de la Iglesia del Hospital de la orden tercer» ${ }^{11}$. Por su parte María Luisa Tárraga localizó otro memorial del escultor en el archivo de Palacio de fecha posterior, ya a finales del siglo, en el que expone que había trabajado para la Enfermería de la V.O.T., un San Antonio, un San Francisco y el resto de la escultura del retablo pero sin mencionar en concreto el grupo de la Inmaculada. Con toda probabilidad es esta escultura, la figura más comprometida y de mayor envergadura del conjunto, lo último realizado, lo que de algún modo podemos apreciar incluso técnicamente en los angelillos de la peana, los mismos que aparecen en otros lugares del retablo, pero ese amaneramiento que detectamos en la Virgen parece haberse transmitido en cierto modo también a algunos de ellos. Hay, por otra parte, frecuentes errores que vemos repetidos en la escasa bibliografía que se ha referido a esta iglesia y es que suele confundirse la capilla de la Enfermería con la capilla del Cristo de los Dolores, ambas de la V.O.T. y muy cercanas entre sí, y además sabemos que para la segunda también talló Julián San Martín otra escultura de San Francisco de Asís que grabó Manuel Salvador Carmona en $1788^{12}$ y que frecuentemente se confunde con el que ahora publicamos. Más extraña es la noticia que hemos localizado en el Tomo XXVII de la colección Suma-Artis, dedicado al arte del siglo XVIII, y en el que aparece fotografiado el San Antonio de la Enfermería con la noticia de ser obra del escultor catalán Luis Bonifás, especificándose incluso estar firmado por éste ${ }^{13}$. Como ya hemos especificado, aquí también se confunden las dos capillas de la V.O.T. y del San Antonio se concreta que está ubicado en la capilla del Cristo de los Dolores. Debido a la rotundidad de la noticia hemos buscado despacio la firma citada sin que haya aparecido por parte alguna, lo cual es perfectamente lógico ya que el estilo de la imagen desmiente esta atribución. Incluso

11 A.D.T., Memorial del escultor Julián San Martín.

12 Varios autores, Arte y Devoción. Estampas de imágenes y retablos de los siglos XVII y XVIII en iglesias madrileñas, catálogo de la Exposición celebrada en el Museo Municipal, Madrid, 1990, p. 77.

13 José Camón Aznar, José Luis Morales y Marín y Enrique Valdivieso González, Arte español del siglo XVIII, Vol. XXVIII de Suma Artis, Madrid, Espasa-Calpe, S.A., 1986, pp. 437 y 438 
es muy posible que cuando la obra se realiza Luis Bonifás hubiese muerto o estuviese a punto de morir.

En la misma iglesia, sobre los pilares achaflanados de la cúpula más cercanos al presbiterio, hay colocadas sobre sencillas peanas dos esculturas de ángeles, uno de ellos representa al Ángel de la Guarda y el otro a San Rafael. De los dos se ha reproducido varias veces, y es figura conocida, el Ángel de la Guarda por su vinculación con modelos de Alonso Cano. El primero en hacerlo, creemos, fue Don Manuel Gómez Moreno en $1926{ }^{14}$, lo exalta sin medida y lo pone en relación con el grupo de mármol que presidía la fachada del convento granadino del Ángel Custodio, conservado hoy en el patio interior, mostrándose más favorable con la versión madrileña por su gracilidad, aunque lo considera repintado. Muy poco después Don Elías Tormo lo considera obra del escultor murciano Juan Porcel ${ }^{15}$. Pero es curioso que ninguno de los dos profesores, excepto para nombarlo, apenas hagan referencia al que tenían enfrente. El hecho lo encontramos especialmente curioso porque el San Rafael (fig. 12) tal vez resulte más agradable y bello y, desde luego, su aire salzillesco resalta más en esta escultura lo que podría abonar su atribución a Juan Porcel que según Sánchez Cantón traería hasta la Corte aires del gran imaginero murciano ${ }^{16}$ y que para Don Elías Tormo «acaso sea el más artista de todos los discípulos de Salzillo» ${ }^{17}$. El San Rafael se eleva sobre idéntica nube y tiene las mismas medidas que su compañero y, al no tener en este caso el escultor un modelo prefijado que imitar, parece moverse con mayor soltura y en un sentido más cercano a su maestro. El tradicional pez no lo porta el arcángel sino que lo lleva abrazado un niño que aparece de pie junto a él, en su lado derecho. Sus formas no son ya fusiformes y sus vestiduras aunque inspiradas en los mismos modelos que las de su acompañante se mueven de modo distinto. Viste doble túnica, de las que la superior llegar hasta el arranque de las piernas y la otra roza el suelo. Como tantas veces ocurre en las reiteradas versiones de estos personajes un tanto andróginos, la túnica se abre por encima del muslo izquierdo dejando entreramente la pierna desnuda aunque calzada con largas botas que llegan por bajo de las rodillas. Una Banda roja le rodea los hombros anudándose bajo el cuello y cayendo graciosamente perdiéndose por la espalda. La policromía es azul en la túnica baja y de un gris azulado en la parte superior, todo resaltado con orlas y dibujos dorados. Según opinión de Don Manuel Gómez Moreno al comentar el ángel de enfrente, tendría la policromía repintada, pero es extremo que no compartimos ya que Don Manuel consideraba estas esculturas más antiguas. El niño viste también túnica azul dejando libre igualmente la pierna izquierda que calza con idénticas botas que las del Ángel. La apostura de esta figura angélica es refinada, sosteniendo con el brazo derecho un cayado de peregrino y con el izquierdo al niño portador del pez. Su rostro dulce y un tanto risueño es típico del momento y del escultor Porcel. Su parecido con los ángeles que acompañaban al San Francisco de la capilla de la V.O.T. del desaparecido convento franciscano de San Gil, llevado y perdido en San Fermín de los Navarros, es evidente en su aire dulce y andrógino y en detalles que se repiten casi exactos, de un modo especial en el ángel izquierdo de los dos que acompañaban al Santo.

14 Manuel Gómez Moreno, «Alonso Cano, escultor», Archivo Español de Arte y Arqueología, N. 6, 1926, pp. 177-214.

${ }_{15}$ Elías Tormo, o.c., p. 63.

16 F. Javier Sánchez Cantón, Escultura y pintura del siglo XVIII, T. XVII de Ars Hispaniae, Madrid, Ed. Plus-Ultra, 1965, p. 264.

17 José Luis Melendreras Gimeno, «Dos estatuas de Juan Porcel para el Palacio Real de Madrid», Reales Sitios, ‥ ${ }^{\circ} 85,1985$, pp. 11-16. 
Y a una última escultura de esta pequeña iglesia queremos hacer mención entre otras cosas por su interés y porque, aunque recientemente ha aparecido publicada en una breve publicación, no parece que se haya reproducido nunca en una revista de investigación artística. Nos referimos a un Cristo crucificado (fig. 13) de tamaño natural que hoy recibe culto en el primer altar de la derecha, entrando desde la calle por la puerta principal. Don Elías Tormo lo señala como una donación del escultor José López y da la fecha de 1782. Añade que, perdido durante las guerras napoleónicas, fue a parar al escultor Pedro Hermoso, lo que nos indica de algún modo que fue una escultura apreciada, y fue devuelta por éste en $1818^{18}$. Muy poco sabemos de este José López, todo indica que será el José López que Cean nos indica fue uno de los primeros alumnos de la Academia participando de modo extraordinario en su primera sesión, celebrada el 13 de junio de 1752, modelando una pieza en barro «con acierto y aclamación... delante de todo el concurso» ${ }^{19}$. Según «Los Registros de Matrícula de la Academia...» publicados por E. Pardo Canalís contaba en ese momento 30 años de edad, su nombre completo era José López y Fernández y debió morir el 22 de febrero de $1788^{20}$. El dato de la edad queda confirmado por otros indicios y documentos publicados por F.J. de la Plaza $^{21}$. Siguiendo a este investigador y más recientemente a María Luisa Tárraga ${ }^{22}$, José López trabajará en las obras del Palacio Real Nuevo de Madrid muy ligado a la órbita de Felipe de Castro. Según F.J. de la Plaza el escultor realizó para Palacio, en piedra de Colmenar, la estatua del rey Reciario de Galicia «que mereció elogios entusiastas y una altísima tasación». Al parecer nos encontramos aquí con una personalidad interesante que tuvo subida estimación en vida y que, muy posiblemente, la falta de un estudio en profundidad nos ha privado hasta casi de su conocimiento. Este Cristo es uno más de ese espléndido conjunto de Crucificados madrileños de los que M. ${ }^{a}$ Elena Gómez Moreno decía no tenía rival sino en el mundo sevillano ${ }^{23}$. Es un Cristo ya muerto, como indica la llaga del costado, de proporciones esbeltísimas y de dibujo y modelado muy correcto pero frío y sin esa garra religiosa que tantos otros Cristos madrileños muestran. Tal vez de los conservados aún en Madrid sea el Cristo de la Buena Muerte del crucero de San Jerónimo el Real, con atribución a Juan Pascual de Mena, el que más parecido tenga con éste por su misma corrección y frialdad que en el caso de la V.O.T. se acentúa. Nos encontramos aquí además con una cabeza sosa, falta de vida, pero unida a un cuerpo de lo más representativo que nos puede mostrar la escultura religiosa del neoclasicismo madrileño. Figuras como ésta nos ponen sobre la pista de escultores apenas conocidos con obras, en ocasiones, interesantes de las que tanto abundan en Madrid y en infinidad de iglesias españolas.

18 Elías Tormo, o.c., p. 63 y Ángel Rivero Izquierdo, Hospital de la V.O.T. de San Francisco de Asís de Madrid, Fraternidad Franciscana Seglar de San Francisco el Grande, Madrid, 1977. En este bello folleto viene reproducido en hermosa fotografía este Crucificado, p. 13.

19 J. Agustín Cean Bermúdez, Diccionario Histórico..., Madrid, 1800, T. III, p. 47.

20 Enrique Pardo Canalís, Los registros de matrícula de la Academia de San Fernando de 1752 a 1815, C.S.I.C., Madrid, 1967, p. 172.

21 F.J. de la Plaza Santiago, Investigaciones sobre el Palacio Real Nuevo de Madrid, Departamento de Historia del Arte. Universidad de Valladolid, 1975.

22 María Luisa Tárraga, Giovan Doménico Olivieri y el taller de escultura del Palacio Real, Patrimonio Nacional, C.S.I.C. e Instituto Italiano de Cultura, Madrid, 1992. Los datos concretos sobre José López aparecen en el Tomo II de esta obra titulado, El Taller y sus vicisitudes.

23 María Elena Gómez Moreno, Escultura del siglo XVII, T. XVI de Ars Hispaniae, Madrid, Ed. Plus-Ultra, 1963, p. 100. 


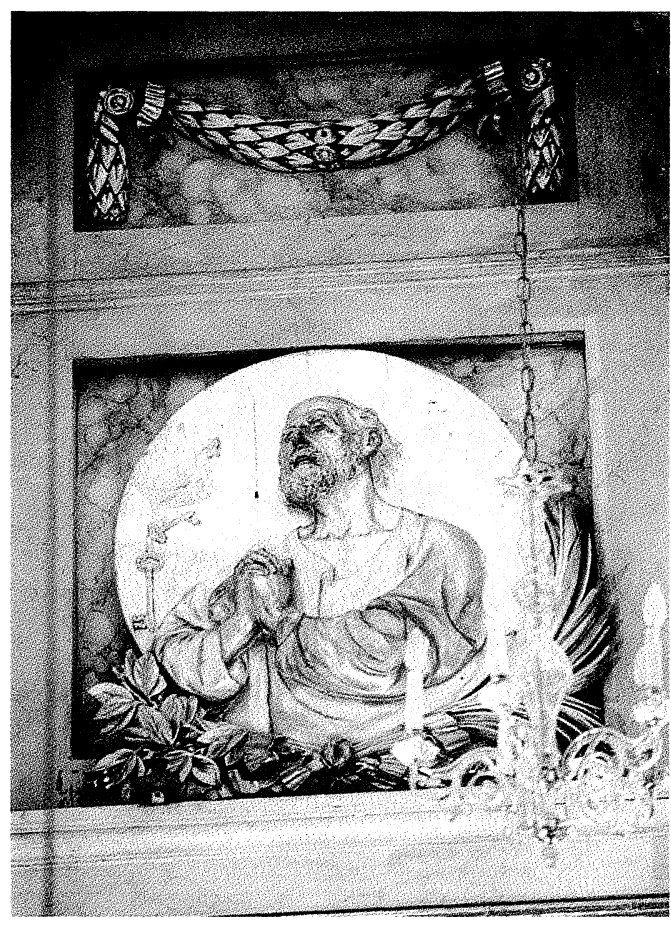

\section{0}
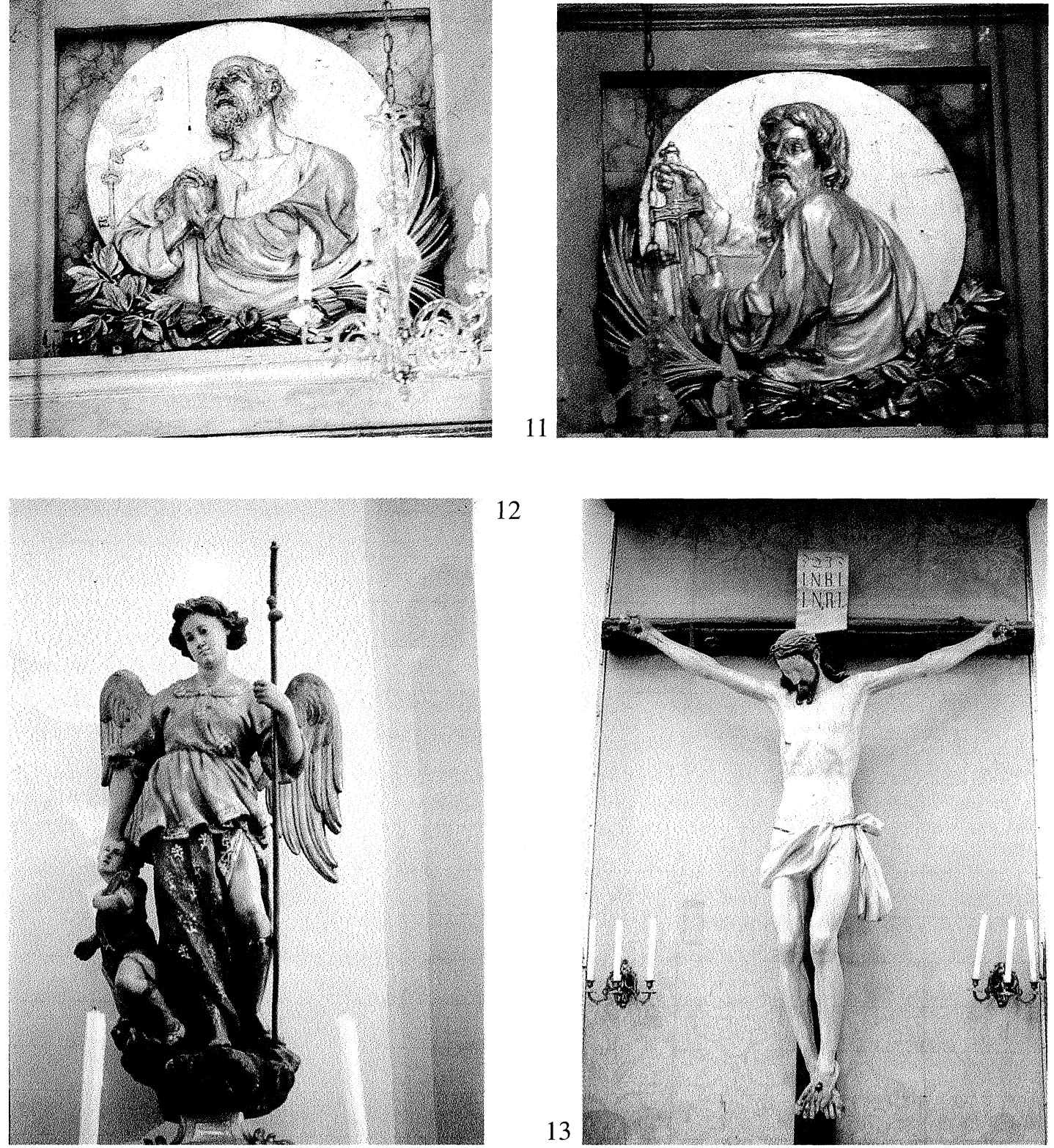

12

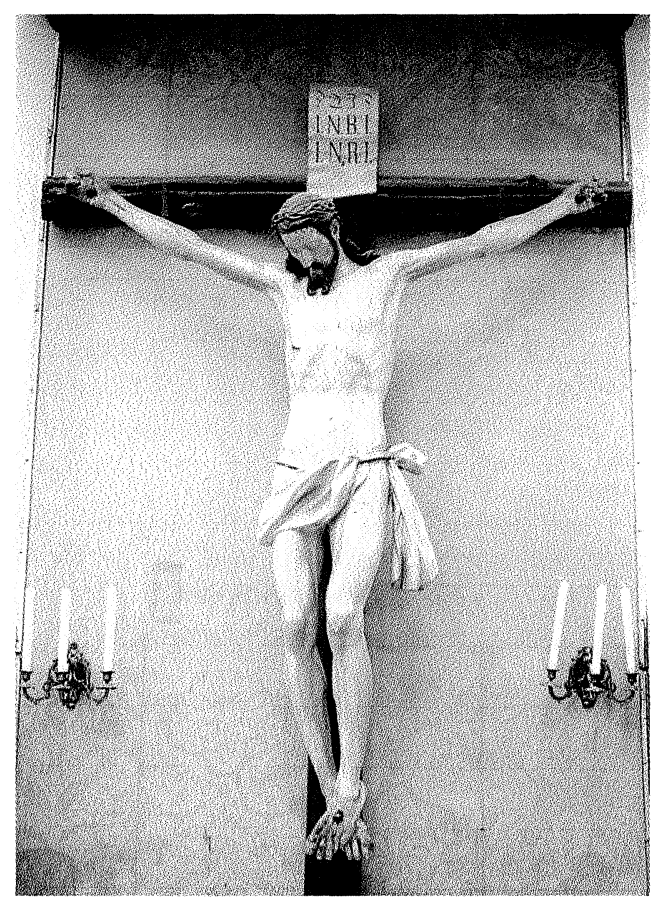

Figuras 10 y 11 . Julián San Martín. Medallones de San Pedro y San Pablo.

Figura 12. Juan Porcel (atrib.). San Rafael.

Figura 13. José López. Crucificado. Madrid. Enfermería de la V.O.T. 
Hasta ahora lo publicado sobre la obra de Julián San Martín era el relieve que preside la fachada de la pequeña iglesia de las llamadas Salesas Nuevas de Madrid que publicó el Doctor Urrea y que debe de ser una de sus últimas obras ${ }^{24}$. Tallado en mármol en él se representa, en una composición correcta y equilibrada, el momento en que San Francisco de Sales entrega a Santa Juana Freniot las constituciones de la Congregación de las Hijas de la Visitación. Pero, como ya hemos dicho, para los no estudiosos San Martín era en realidad conocido exclusivamente por su Beata María Ana de Jesús que recibe culto en el altar lateral del crucero de la parroquia madrileña de Santiago donde la Beata fue bautizada, y la escultura se hace al hilo de su beatificación en $1783^{25}$. Obra enormemente popular en el Madrid devocional, de figura muy bien plantada, vestida con el hábito mercedario de paños finos y elegantemente movidos y que debe mucho de su fama al realismo del rostro trabajado ante la mascarilla que a su muerte se hace. De ella se hicieron diversas versiones o bocetos. Hasta hace no muchos años hubo uno en la misma parroquia de Santiago y otro se ha publicado recientemente conservado en el Victoria and Albert Museum de Londres. Trabajado en terracota procede, al parecer, de Valladolid donde pudo ser adquirido en el siglo pasado ${ }^{26}$.

\section{Apéndice documental}

Memorial del escultor Julián San Martín. Archivo Diciocesano de Toledo.

$$
\mathrm{Em}^{\mathrm{mo}} \text { Señor }
$$

Señor

$\mathrm{D}^{\mathrm{n}}$ Julian de S. Martín, Académico de mérito de la Rl. Academia de $\mathrm{S}^{\mathrm{n}}$ Fernando en la clase de escultura, a V. $\mathrm{Em}^{\mathrm{a}}$ hace presente tiene ejecutadas varias obras públicas pertenecientes a su Arte para esta Corte y fuera de ella; y entre otras la estatua de la Beata Mariana de Jesús $\mathrm{p}^{\mathrm{a}}$ la Iglesia de Santiago; el descanso de $\mathrm{N}^{\mathrm{a}} \mathrm{S}^{\mathrm{ra}}$ de la Capilla de los Maestros de Obras de $S^{n}$ Sebastián por Dirección del $S^{r} D^{n}$ Manuel Alvarez Direct ${ }^{r}$ gral de la Academia; y toda la obra nueva de escultura del Altar mayor de dha Parroquia: Toda la escultura del retablo de la Iglesia del Hospital de la orden tercera de $S^{n}$ Fran $^{\text {co }}$ y los Angeles del retablo mayor de la Parroquia de $S^{n}$ Mig $^{1}$ y una estatua de $\mathrm{N}^{\mathrm{a}} \mathrm{S}^{\mathrm{ra}}$ de la caveza $\mathrm{p}^{\mathrm{a}}$ su retablo en la Parroq ${ }^{\mathrm{a}}$ de $\mathrm{S}^{\mathrm{n}}$ Justo; en esta atención; y en la de desear la ejecución de algunas obras en servicio de V. Em ${ }^{\mathrm{a}}$ y que podran informar de su mérito el $\mathrm{S}^{\mathrm{r}} \mathrm{D}^{\mathrm{n}} \mathrm{Man}^{1}$ Alvarez, $\mathrm{D}^{\mathrm{n}}$ Antonio Pons o quien fuere de su agrado.

$\mathrm{Sup}^{\mathrm{ca}}$ a V. Em ${ }^{\mathrm{a}}$ le tenga presente para encomendarle alguna de las estatuas que de orden de V. Em ${ }^{\mathrm{a}}$ se han de colocar en la fachada exterior del Rl. Combento de las Salesas, como también otra qualquiera obra que sea del agrado de V. Em ${ }^{\text {a }}$ en que recivirá particular favor. Madrid 5 de julio de 1789.

Julian de $S^{\mathrm{n}}$ Martín

24 Jesús Urrea, o.c., p. 131.

25 Exposición conmemorativa del primer Centenario de la Diócesis de Madrid-Alcalá, 1986, pp. 206-207 y Virgilio Bermejo, «Sta. Catalina de Siena y la génesis del retrato de la beata madrileña María Ana de Jesús (1564-1624)», Archivo Español de Arte, N.. 276, 1996, pp. 450-456.

26 Marjorie Trusted, Spanish Sculpture. Catalogue... in the Victoria and Albert Museum, 1996, pp. 75-76. 